\title{
Predictors of Wound Healing Following Revascularization for Chronic Limb-Threatening Ischemia
}

\section{Antonopoulos, Constantine N.}

2019-11

Antonopoulos , C N , Lazaris , A , Venermo , M \& Geroulakos , G 2019 , ' Predictors of Wound Healing Following Revascularization for Chronic Limb-Threatening Ischemia ' , Vascular and Endovascular Surgery , vol. 53 , no. 8 , 1538574419868863 , pp. 649-657 . https://doi.org/10.1177/153

http://hdl.handle.net/10138/320949

https://doi.org/10.1177/1538574419868863

publishedVersion

Downloaded from Helda, University of Helsinki institutional repository.

This is an electronic reprint of the original article.

This reprint may differ from the original in pagination and typographic detail.

Please cite the original version. 


\title{
Predictors of Wound Healing Following Revascularization for Chronic Limb-Threatening Ischemia
}

Vascular and Endovascular Surgery

2019, Vol. 53(8) 649-657

(C) The Author(s) 2019

Article reuse guidelines:

sagepub.com/journals-permissions DOI: I0.I I77/I5385744|9868863

journals.sagepub.com/home/ves

@SAGE

\author{
Constantine N. Antonopoulos, MD'®), Andreas Lazaris, MD', \\ Maarit Venermo, MD ${ }^{2}$, and George Geroulakos, MD'
}

\begin{abstract}
Objectives: After surgical or endovascular revascularization, some ischemic lesions will not heal, while some others will heal at a variable period of time from the intervention, indicating a multifactorial interaction between local and systematic "wound healingpromoting" factors. Our objective was to identify predictors of wound healing following revascularization for chronic limbthreatening ischemia (CLTI). Methods: A literature review was performed to identify published research concerning clinical, biochemical, and noninvasive methods as predictors of wound healing time and wound-free period after surgical and endovascular revascularization for CLTI. Results: Our review indicated that potential predictors included local wound factors, wound depth, patient's comorbidities, medications, smoking and alcohol abuse, poor vessel runoff, and direct versus indirect revascularization. Among the clinical biomarkers, platelet-derived growth factor, transforming growth factor $\beta$, basic fibroblast growth factor, tumor necrosis factor $\alpha$, interleukin (IL) I, and IL-6 have been proposed as potential predictors. Furthermore, the potential of noninvasive microcirculation assessment to predict proper wound healing has been the topic of extensive investigation. Among the novel methods, transcutaneous measurement of oxygen partial pressure, skin perfusion pressure, oxygen-to-see method, indocyanine green fluorescence imaging, and multispectral optoacoustic tomography have shown promising results. Conclusions: The risk factor profile of an ischemic lesion in the lower extremities with a delayed/failed healing response, following a successful revascularization, is not fully clarified. Although many predictors have been assessed so far, further research needs to be done to identify the optimal clinical and biochemical indices and the noninvasive technique assessing the microcirculation that is associated with complete wound healing.
\end{abstract}

\section{Keywords}

wound healing, revascularization, chronic limb-threatening ischemia, biomarkers

\section{Introduction}

Chronic limb-threatening ischemia (CLTI), also referred as critical limb ischemia, chronic critical limb ischemia, or severe limb ischemia, is a proxy of lower extremity arterial disease (LEAD), and it is characterized by chronic, inadequate tissue limb perfusion at rest. ${ }^{1}$ It is clinically defined as ischemic rest pain in the foot lasting more than 2 weeks, nonhealing wound, or gangrene that is attributable to objectively proven arterial occlusive disease. ${ }^{1}$ The CLTI has been linked to decreased quality of life and substantial morbidity and mortality, ${ }^{1}$ and as a result, surgical or endovascular revascularization is regarded as the standard of care in mobile independently living patients. ${ }^{2,3}$

Complete wound healing and relief from ischemic symptoms are the main goals after surgical or endovascular revascularization for CLTI. However, it has been reported that a year following revascularization, only $75 \%$ of the ischemic ulcers are completely healed. ${ }^{4}$ It has been proposed that a multifactorial model is probably more appropriate to accommodate for the complex interaction between local and systematic "wound healing-promoting" factors.

In this study, we have reviewed the current literature concerning clinical, biochemical, and noninvasive methods as predictors of wound healing time and wound-free period after surgical and endovascular revascularization for CLTI.

Wound healing incorporates a complex biological process in which many parallel and interrelated pathways are activated

\footnotetext{
'Department of Vascular Surgery, "Attikon” University Hospital, Athens, Greece

${ }^{2}$ Department of Vascular Surgery, Abdominal Center, University of Helsinki and Helsinki University Hospital, Helsinki, Finland
}

\section{Corresponding Author:}

Constantine N. Antonopoulos, Department of Vascular Surgery, "Attikon" University Hospital, Athens, Greece.

Email: kostas.antonopoulos@gmail.com 
Table I. Risk Factors for Delaying Wound Healing after Lower Limb Revascularization.

Local wound factors

Patient's comorbidities

Lifestyle factors

Poor runoff and indirect revascularization (nonangiosome targeted)

and synchronized in order to induce the optimal wound repair. Hemostasis, inflammation, cellular proliferation, and remodeling are the 4 known wound healing phases. ${ }^{5}$ Oxygen plays a central role in each step of the healing process, and it is also essential for collagen deposition as it acts as a substrate in the hydroxylation of proline and lysine residues. The LEAD interrupts this normal process by creating a system of localized hypoxia that chronically impairs proliferation by decreasing neoangiogenesis.

\section{Risk Factors for Delaying Wound Healing After Lower Limb Revascularization}

1) Local wound factors affecting healing. The role of negative pressure wound therapy, antibiotics, and hyperbaric oxygen therapy.

Despite a successful limb revascularization and restoration of oxygen delivery to the peripheral tissues, delayed wound healing time may be affected by local wound factors (Table 1). ${ }^{6}$ In a dry environment, cells typically dehydrate and die. Desiccation is an important local factor for delayed wound healing, while local hydration with a moisture-retentive dressing substantially improves outcomes. Local infection or abnormal bacterial presence usually produces purulent drainage or exudate and requires attention. Maceration or local trauma may increase healing time, while any tissue necrosis, slough, or eschar should be removed to accelerate healing. ${ }^{6}$ Removal of these local factors keeps the wound clean and enhances granulation. However, constant manual washout is impossible. For that reason, negative pressure wound therapy (NPWT) has been developed. It involves the application of a wound dressing attached to a vacuum suction machine, which applies a carefully controlled negative pressure to the wound and sucks debris and tissue fluid away from the treated area into a canister. Promising results have been published in the literature in the past, indicating that NPWT is efficacious, safe, and cost-effective in treating diabetic foot ulcers (DFUs). ${ }^{7}$ However, a recent Cochrane meta-analysis has been more skeptical, indicating that there is only low-certainty evidence to suggest that NPWT, when compared to wound dressings, may increase the proportion of wounds healed and reduce the time to healing for postoperative foot wounds and ulcers among diabetic patients. ${ }^{8}$

Another important factor when trying to eliminate local wound factors that decrease wound healing rate is the use of antibiotics. Although very useful, there is no indication for their use in uninfected foot wound as either infection prophylaxis or for accelerating wound healing. ${ }^{9}$ A detailed advice on empirical antibiotic therapy that may be used as a framework for local guideline development to support clinicians in the management of diabetic foot infection was published by Barwell et al. ${ }^{10}$

Concerning other types that promote wound healing in the local microenvironment, hyperbaric oxygen therapy (HBOT) has shown conflicting result. In a recent meta-analysis, the authors have found that HBOT was associated with a greater reduction in the ulcer wound area than standard therapy. ${ }^{11}$ However, clinically oriented practice literature has suggested that only a moderate level of evidence supports the use of HBOT, and a shared decision-making should be always followed. $^{12}$

Finally, among other local factors, pressure to the wound area is important and common in patients who have neuropathy. Pressure does not only cause wounds but also prevents healing after revascularization. Among them, total contact casts were found to be the most effective devices to achieve ulcer healing. However, they are not without complications and their impact on cost, compliance, and quality of life is not well understood. $^{13}$

2) Clinical effect of wound depth and area upon healing time

Although vascular surgeons commonly use the Rutherford classification, no wound depth information is included in this classification system and thus follow-up on patient's wound healing progress after revascularization is mainly clinical and subjective. Texas classification has been used for decades to describe the depth of the wound, and a recent study underlined that deep wounds were associated with a high rate of complicating infection, lower wound healing rate, and a longer time to wound healing. ${ }^{14}$ Two years ago, Wound, Ischemia, and foot Infection (WIfI) classification was introduced and recommended to be used in patients with foot ulcer. The WIfI does not only grade wound depth but also the severity of ischemia and infection and thus predicts better the risk of amputation and need for revascularization. ${ }^{15}$ Naturally, deeper wounds require more infection control and advanced wound management compared to more shallow wound ulcers. Not only the depths of the wound but also the area is important: The higher is the number 
of affected angiosomes by wound, the longer is the time needed for wound healing. ${ }^{16}$

3) Patient's comorbidities as factors delaying response to tissue injury in LEAD patients

Diabetes mellitus (DM) is probably the most important risk factor. Peripheral neuropathy leads to decreased sensation of the foot, while autonomic neuropathy produces skin trophic changes. ${ }^{17}$ These mechanisms usually result in increased risk of secondary infection, which further impairs the proliferating phase by impairing fibroblast signaling and resulting in poor granulation tissue formation. Diabetic foot management, apart from proper revascularization, includes off-loading casting or orthotics to equalize plantar pressure and moist dressings and debridement to restore a balanced environment. ${ }^{18}$ Furthermore, in patients with diabetes, the anatomical configuration of the foot changes leads to pathological distribution of skin compression, and due to neuropathy, the pain sensation that protects the skin is impaired, leading to ulcers. This same mechanism impairs would healing, and the offloading therapy is usually required to allow the wound to heal. More recent healing techniques have shown promising results, like combination of total casting with cryopreserved human fibroblast-derived dermal substitute or HBOT. Notably, in a study investigating risk factors for DFU over a period of 15 years among $25220 \mathrm{ft}$ from 5588 patients with T1 DM and 7113 patients with T2 DM, the authors ${ }^{19}$ have concluded that male sex, age $>60$ years, high hemoglobin A1C (HbA1c), long diabetes duration, history of cardiovascular disease, macro-albuminuria, decreased visual acuity, advanced diabetic retinopathy, decreased/absent vibration sense, presence of patient reported symptoms of neuropathy, and absence of foot pulses were independent risk factors for the development of first time DFU in T1 DM. In T2 DM, the independent risk factors were the same except age $>60$ years, a history of cardiovascular disease, and long diabetes duration. Interestingly, glycemic variability - the visit-to-visit variation in $\mathrm{HbA1c}$ - seems to play very important role in the development of micro- and macrovascular disease in patients with diabetes. In a relevant study ${ }^{20}$ ulcers in patients with low $\mathrm{HbAlc}(<58 \mathrm{mmol} / \mathrm{mol})$ and low variability healed faster than those in patients with high $\mathrm{HbAlc}$ and high variability.

Chronic kidney disease (CKD) has been shown to be independently associated with decreased wound healing in Rutherford category 5-6 patients, despite successful revascularization (hazard ratio [HR]: $0.45,95 \%$ confidence intervals [CI]: 0.25 $0.83, P=.010) .{ }^{21}$ Chronic kidney disease impairs wound healing due to its complications such as uremia, anemia, and fluid overload. Furthermore, CKD impairs the healing after transmetatarsal (TMT) amputation and predicts the failure of TMT amputation (odds ratio [OR]: $2.00,95 \% \mathrm{CI}: 1.1-3.52$ ). ${ }^{22}$ Furthermore, hemodialysis seems to be a very important predisposing factor for delayed wound healing. In a study by Das et $\mathrm{al}^{23}$ wound healing rates were analyzed retrospectively in patients who underwent successful below-the-knee percutaneous transluminal balloon angioplasty for CLTI with tissue loss. The authors found that patients with end-stage renal disease receiving dialysis were 2.6 times more prone to wound nonhealing.

Obesity is another contributing factor mainly due to avascularity of the surrounding adipose tissue, which decreases the resistance to infection secondary to oxygen deprivation. This, in turn, compromises collagen and oxygen-dependent cellular repair processes. A further decreased mobility and inability to optimally reposition oneself make wound healing problematic. ${ }^{24}$ Other potential mechanisms include vascular insufficiencies, cellular and composition modifications, oxidative stress, alterations in immune mediators, nutritional deficiencies, and plausible alterations and deficiencies in obese individuals. $^{25}$

Malnutrition may also result in decreased wound healing. Decreased collagen production, angiogenesis, and fibroblast proliferation are the shared pathophysiological features among the disease states that are influenced by low protein intake. Low serum albumin has been linked with the development of pressure ulcers. Moreover, vitamin C deficiency contributes to fragile granulation tissue, while lack of fatty acids threatens integrity of cell structure. ${ }^{26}$ As a result, holistic assessment of nutrition and nutritional support and replacement therapy may be necessary after a successful revascularization to promote wound healing. ${ }^{18}$

\section{4) Medications that may impact wound proliferation}

Nonsteroidal anti-inflammatory drugs show an antiproliferative effect on blood vessels and skin while decreasing the granulocytic inflammatory reaction, thereby delaying healing time. Furthermore, the anti-inflammatory and immunosuppressant actions of steroids have found to impede wound contraction and decrease tensile strength; thus, they negatively affect wound healing. More specifically, glucocorticoids inhibit local wound fibroblast proliferation and decrease collagen production, while they systematically increase blood glucose and inhibit immune system, which further delays wound maturation. ${ }^{27}$ Moreover, chemotherapeutic agents, such as adriamycin and bevacizumab, have been implicated for delayed wound healing in patients with cancer mainly mediated by delayed inflammatory phase of healing, decreased fibrin deposition, and collagen synthesis and delayed wound contraction. ${ }^{18}$

5) Smoking and alcohol abuse as lifestyle factors implicated in wound healing phases

Smoking is highly prevalent among patients with LEAD. Its effect is mediated through vasoconstriction, stimulation of accelerating tissue destruction proteases, and immunosuppression that leads to increased risk of infection. Additionally, platelet activation and subsequent clot formation increase fibrinogen, which further leads to connective tissue degradation, while carbon monoxide negatively affects oxygen delivery to healing wounds. ${ }^{28}$ Insulin resistance, hyperglycemia, low protein intake, and high likelihood of infection, usually 
associated with alcohol abuse, are negative wound healing prognostic factors after revascularization in these patients. ${ }^{29}$

6) The use of vessel runoff and direct versus indirect revascularization in predicting wound healing time

As oxygen is the requirement for the successful wound healing, revascularization should aim to restore as good arterial circulation as possible in the wound area. A strong association between change in ankle-brachial index (ABI) and toe-brachial index and outcomes following revascularization has been shown. In a study by Reed et al, ${ }^{30}$ change in $A B I \geq 0.23$ was independently associated with wound healing and less repeat revascularization. Although clinically appealing, results of single- versus multiple-vessel infrapopliteal intervention have shown that multiple-vessel intervention did not improve outcomes. ${ }^{31}$ The vascular surgeon should always assess the diabetic foot first with the possibility for revascularization, before amputation is considered. Adequate initial arterial tissue perfusion may lead to a less extensive amputation. However, early recognition and aggressive surgical drainage of foot sepsis followed by surgical revascularization is sometimes mandatory. ${ }^{32}$

Although revascularization represents the primary therapy for DFU, a more "targeted and localized approach" has been proposed. According to the angiosome theory, revascularization of the angiosome where the wound exists (angiosometargeted revascularization) leads to better wound healing and limb salvage compared to the so-called nontargeted revascularization, where the wound angiosome gets circulation through collaterals from the artery that has been revascularized. There are several retrospective studies which have shown that wound healing is more comprehensive and faster after targeted revascularization than nontargeted revascularization. ${ }^{33}$ Most of these studies include only endovascular revascularizations, and indeed, also some evidence exists that after surgical bypass the difference in wound healing between targeted and nontargeted revascularization is smaller. ${ }^{16}$ According to criticism regarding the angiosome concept, the presence of collateral vessels should provide adequate inflow to the entire foot after bypass to any of the 3 crural arteries, irrespective of the type of revascularization. ${ }^{34}$

\section{7) Wound location}

Ischemic tissue lesions located in the mid- and hindfoot has significantly prolonged ulcer healing time after revascularization compared to wounds that are located in forefoot or crural area (HR: 0.4, 95\% CI: 0.1-0.9). ${ }^{35}$ The reason for this is probably multifactorial. The heel area is often under pressure when patient is lying in the bed, and decompression may be insufficient. Furthermore, if neuropathy impairs the feeling of pain, there is no signal need to change the position. Another factor may be arterial circulation to the heel area, which is poor in many patients, and despite good revascularization, the arteries leading to the wound area in the heel may be occluded.

\section{Risk Stratification Models and Time to Heal Predictors After Revascularization}

Although it is recognized that ulcer healing is a useful proxy of successful revascularization for CLTI, not all studies report this. Interestingly, a review ${ }^{2}$ has found that among 1914 articles on revascularization, complete ulcer healing was reported only in $17(0.9 \%)$ studies. In a study assessing 871 critically ischemic limbs treated with endovascular approach, the authors found that the rate of freedom from major amputation at 1 year reached $88 \%$, whereas the wound healing rate was $67 \%$, and the median time to wound healing was 146 days. ${ }^{34}$ Their risk stratification model estimated that nonambulatory status, low albumin level, Rutherford 6 category, wound infection, indirect intervention, and poor below-ankle runoff were independent predictors for delayed wound healing. After infrainguinal bypass, another study ${ }^{4}$ demonstrated that complete tissue healing, including healing of ischemic tissue lesions and surgical wounds, at 6 and 12 months were $40 \%$ and $75 \%$, respectively, whereas the median time to complete tissue healing was 190 days. Diabetes was the only significant moderator. A similar study ${ }^{35}$ evidenced a $74 \%$ complete ulcer healing at 12 months after the bypass. Interestingly, ischemic tissue lesions located in the mid- and hindfoot had significantly prolonged ulcer healing time. Concerning decision between open and endovascular revascularization, both strategies have shown good results. However, it seems that although contemporary use of endovascular therapies may result in the avoidance of open surgery in some patients, the injudicious use of catheter-based therapies may sometimes lead to diminished success for open surgical revascularization, potentially hampering a long-term benefit. As a result, vascular surgeons should be equipped with both open and endovascular skills when attempting to provide optimal vascular care for wound healing. ${ }^{36}$

Concerning the impact of direct versus indirect revascularization upon healing time, an interesting study ${ }^{37}$ showed that median ulcer healing time was significantly lower (56 \pm 18 days) in the direct group, compared to $112 \pm 45$ days in the indirect group. These findings were also confirmed by another study. ${ }^{38}$ On the contrary, a study ${ }^{39}$ assessing outcomes after distal bypass concluded that only the location and the extent of the ischemic wounds as well as comorbidities may be more relevant than the angiosome in terms of wound healing. However, this study did not investigate whether the collateral development was sufficient or whether the arterial disease involved the connecting arteries between angiosomes. In a study on 545 patients with diabetes and ischemic tissue lesion comparing angiosome-targeted versus nontargeted both surgical and endovascular revascularization, 1-year wound healing was best (77\%) after targeted bypass and worst after nontargeted angioplasty (52\%). In this study, also collaterals between angiosomes and their influence were analyzed. And indeed, in patients who underwent indirect angioplasty, the 1-year wound healing was significantly better when collaterals between angiosomes existed. ${ }^{40}$ The Cox proportional hazards analysis revealed that angiosome-targeted revascularization, bypass surgery, 
C-reactive protein $\leq 10 \mathrm{mg} / \mathrm{dL}$, and the fewer angiosomes affected improved wound healing. Interestingly, indirect bypass surgery also achieved better wound healing rates than angioplasty independent of the angiosome oriented strategy. What is more, another study ${ }^{41}$ proposed that significant predictors of sufficient wound healing after revascularization included normal renal function, a palpable postoperative pedal pulse, a patent posterior tibial artery past the ankle, and the number of patent tibial arteries after bypass to the ankle. A list of studies reporting on time to wound healing is presented in Table 2.

\section{The Need for More "Sophisticated" Indices of Assessing the Wound Healing Process After Revascularization}

Biomarkers. Although historical outcomes, such as graft patency, amputation-free period, target lesion revascularization, are still considered reliable indicators of wound healing process, there is a demanding need for more accurate predictors. Among them, $\beta-2$-microglobulin, cystatin $\mathrm{C}$, highsensitivity C-reactive protein, and glucose have been traditionally involved as predictors among LEAD patients (Table 3). Other biomarkers of vascular remodeling include the transforming growth factors $\beta 1$ (TGF- $\beta 1$ ), the soluble receptor for advanced glycation end products, and the plasma thrombospondin, while it is under investigation whether the number of circulating endothelial progenitor cells (EPCs) may be of value as a reliable biomarker for LEAD.

Although all these indices have been proposed as surrogates of LEAD severity, ${ }^{49,50}$ there is currently no consensus on which of these biomarkers may be used to reliably assess microcirculation after revascularization. ${ }^{51}$ For that reason, many more biomarkers have specifically tested for the purpose of evaluating the wound healing process in each of the 4 healing phases. ${ }^{52}$ In phase I (hemostasis), the platelet-derived growth factors (PDGF), along with the vascular endothelial growth factors (EGFs), fibroblast growth factors (FGFs), and TGFs play an important role and have been tested as proxies of ongoing wound. In phase II (inflammation), many growth factors and cytokines, like PDGF, TGF- $\beta, \beta$-FGF, TNF- $\alpha$, interleukin (IL) 1 , and IL-6, which promote the proliferative phase of healing, may be used as good biomarkers of promoting wound healing. In phase III (proliferation), the main process is the proliferation and migration of the epithelial cells, which starts with the production of the matrix metalloproteinases (MMPs) with the aid of EGF, keratinocyte growth factors (KGFs), and TGF- $\alpha$, while in the last phase of remodeling, the number of fibroblasts begins to reduce. Interestingly, studies have demonstrated that IL-1, IL-6, and MMPs, levels above normal, and an abnormally high MMP-tissue inhibitor of metalloproteases ratio are often present in nonhealing wounds. Apart from these, gene expression has been also tested, with promising results, while there is currently great interest in designing and applying a benchmark to identify and validate pathogenic and nonpathogenic biomarkers of wound healing; among them, serpinB3 has been identified as a healing wound biomarker in diabetic patients. ${ }^{53}$
Modern noninvasive methods evaluating the process of wound healing. The microcirculation as an additional important factor of wound healing may be also assessed by novel noninvasive methods. Among them, the transcutaneous measurement of oxygen partial pressure $\left(\mathrm{TcpO}_{2}\right)$ is a polarographic method to measure $\mathrm{pO}_{2}$ at the skin surface. The $\mathrm{TcPO}$ is measured using skin surface sensors at $43^{\circ} \mathrm{C}$ to $45^{\circ} \mathrm{C}$, it is accurate in noncompressible arteries, and it can be used in diabetic and renal patients, while a TcPO2 level below a cutoff of 20 or $30 \mathrm{~mm}$ $\mathrm{Hg}$ is an independent predictor of complications during chronic wound healing. Another index of microvascular circulation is the skin perfusion pressure (SPP). Three different types of techniques are currently used for the measurement of SPP, namely, radioisotope clearance, photoplethysmography, and laser Doppler. Among them, laser Doppler is fast, effective, and easy to operate and is the most widely used method of measuring SPP. ${ }^{54}$ In a study by Yamamoto et al, the authors have found that an increase in SPP of $\geq 20 \mathrm{~mm} \mathrm{Hg}$ after bypass surgery was associated with better limb prognosis. ${ }^{55}$

Novel noninvasive techniques include the oxygen-to-see method, which is an optical measuring technique that combines white light spectrometry and laser Doppler flowmetry, mapping oxygen saturation, relative hemoglobin, and blood flow in target tissues. More interestingly, indocyanine green fluorescence imaging (ICG-FI) enables the visualization of perfusion of the entire foot and quantifies the washout of ICG in the peripheral tissues. Using time-intensity curve extracted from the ICG-FI record, the perfusion can be quantified. ${ }^{56}$ The ICGFI is a promising tool in the assessment of change in foot perfusion after revascularization as well as quality control of the procedure. ${ }^{57,58}$ More studies are needed to assess the value of ICG-FI in the wound healing. Another novel method of microcirculation assessment, namely, the multispectral optoacoustic tomography, combines optical imaging with conventional ultrasound. The target tissue is illuminated with pulsed laser light in the near-infrared range, allowing visualization of even the tiny arterioles of the foot microcirculation up to a diameter of $100 \mu \mathrm{m} .{ }^{59}$ Although these methods seem quite promising in assessing the outcome after revascularization and prognose wound healing, more studies are needed before it can be implemented in the everyday practice.

\section{Conclusions}

Wound healing is a continuous process that combines a cascade of events leading to repair and regeneration of a local tissue trauma. However, there are many intrinsic and extrinsic factors that may delay or completely interrupt this procedure. Among them, local wound factors, wound depth, patient's comorbidities, medications, lifestyle factors, poor runoff, and indirect revascularization have been implicated. Further research needs to be done to identify the optimal biomarker profile that is associated with the wound healing process. In addition, we need more reliable noninvasive methods to predict the healing potential of the wound. 
Table 2. Studies Reporting on Time to Wound Healing After Lower Limb Revascularization.

\begin{tabular}{|c|c|}
\hline Study & Inclusion Criteria \\
\hline Okazaki et al $(2018)^{42}$ & $\begin{array}{l}233 \text { patients with CLI and tissue loss who underwent } \\
\text { surgical or endovascular revascularization of the } \\
\text { infrainguinal vessels were reviewed retrospectively }\end{array}$ \\
\hline Spillerova et al $(2015)^{16}$ & $\begin{array}{l}744 \text { ( } 252 \text { propensity score matched pairs) patients with } \\
\text { CLI and tissue lesion }\end{array}$ \\
\hline Lejay et al $(2014)^{37}$ & $\begin{array}{l}58 \text { consecutive CLI limbs of } 54 \text { diabetic patients } \\
\text { presenting with tissue loss who underwent isolated } \\
\text { BTK bypasses for crural occlusive arterial disease }\end{array}$ \\
\hline Kret et al $(20 \mid 4)^{43}$ & $\begin{array}{l}97 \text { patients who had tibial/pedal bypass for a foot/ankle } \\
\text { wound were identified and operations classified as } \\
\text { direct revascularization (DR) or indirect } \\
\text { revascularization (IR) based on wound location and } \\
\text { bypass target }\end{array}$ \\
\hline Azuma et al $(20 / 2)^{39}$ & $\begin{array}{l}28 \mathrm{CLI} \text { patients with tissue loss who underwent distal } \\
\text { bypasses were reviewed }\end{array}$ \\
\hline
\end{tabular}

Neville et al (2009) $)^{44}$

48 patients with nonhealing lower extremity wounds requiring tibial bypass
Outcomes-Time to Wound Healing

The mean wound healing time in the subgroup of limbs that achieved wound healing $(n=196)$ was I43.7 days

Angiosome-targeted revascularization, I-year wound healing 67.3\%; angiosome nontargeted revascularization, I-year wound healing $71.6 \%$

Median ulcer healing time was $56 \pm 18$ days in direct group $(n=36)$ and $112 \pm 45$ days in indirect group $(\mathrm{n}=22, \mathrm{P}=.0 \mathrm{I})$

Complete wound healing ( $78 \%$ vs $46 \% ; P=.001)$ and time to complete healing ( 99 vs 195 days; $P=.002$ ) were superior with DR vs IR

The median ulcer healing time was 47 days in nonrenal patients with Rutherford category (R) 5, 73 days in renal patients with $\mathrm{R} 5$, I I 5 days in nonrenal patients with R6, and 237 days in renal patients with R6

$77 \%$ of wounds $(n=33)$ progressed to complete healing and $23 \%$ of wounds $(n=10)$ failed to heal with resultant amputation. In the DR group, there was $91 \%$ healing with a $9 \%$ amputation rate. In the IR group, there was $62 \%$ healing with a $38 \%$ amputation rate $(P=.03)$. In those wounds that did heal, total time to healing was not significantly different in DR (162.4 days) versus IR (I59.8 days)

Soderstrom et al (2008) ${ }^{4} \quad$ I 48 patients with CLI and tissue loss (Fontaine IV) were The median time to complete tissue healing was I 90 days followed prospectively for I year after infrainguinal bypass

Atar et al $(2005)^{45}$

38 elderly patients (mean age 83.3 years) with CLI were treated with percutaneous balloon angioplasty

Mlekusch et al $(2002)^{46} \quad 40$ patients with ischemic ulcers (Fontaine stage IV) undergoing percutaneous transluminal angioplasty (PTA)

Brochado et al (2000) ${ }^{47}$ II patients with grade III CLI in whom arteriography showed femoropopliteal occlusive disease and at least one genicular branch suitable for receiving a bypass

Treiman et al $(2000)^{4 l}$

9I patients were treated for heal wounds that did not heal for I to 12 months (62\% of nonhealing wounds, 3 months or longer). Infrainguinal bypass was performed for $8 \mathrm{I}$ patients, 4 had inflow procedures, 3 had superficial femoral artery percutaneous transluminal angioplasty, and 3 had primary below-knee amputation

Nicoloff et al $(1998)^{48} \quad 12$ patients who underwent initial infrainguinal bypass surgery for limb salvage
Healing of the wounds took between I and 7 months (average $4.45 \pm 2.16)$. In 7 patients ( 4 with ischemic wounds and 3 with rest pains), their symptoms did not improve after the percutaneous balloon angioplasty. Four patients had subsequent leg amputations and 3 needed revascularization surgery within the I-year follow-up

The median healing interval was 5 months (IQR $2 \pm 7$ ). A reappearance of ulcers was found in 9 patients (22\%)

Over a median time of 19 months (range 6-43 months), one of the patients showed no clinical improvement. Of the 8 patients who had a patent graft, the Doppler ankle-brachial systolic pressure index showed no change in I patient, an increase in 6 patients, and was not measured in I patient. The former patient underwent a below-knee amputation, whereas the other 7 patients showed complete healing of their skin ulcers and sites of minor amputation

Sixty-six (73\%) of the heel ulcers healed, 14 (16\%) remained nonhealed, and II patients (II\%) eventually underwent BKA. For the wounds that healed, the interval from interventional treatment to healing ranged from I to 6 months (mean, 3.2 months)

Wound (operative and ischemic) healing required a mean of 4.2 months (range, $0.4-48$ months) and 25 patients (22\%) had not achieved complete wound healing at the time of last follow-up or death 
Table 3. Various Biomarkers for Assessing the Progress of Wound Healing.

\begin{tabular}{|c|c|}
\hline PAD predictors & $\begin{array}{l}\beta \text {-2-microglobulin (B2M), cystatin C, high- } \\
\text { sensitivity } C \text {-reactive protein (hsCRP), } \\
\text { glucose }\end{array}$ \\
\hline Vascular remodeling & $\begin{array}{l}\text { transforming growth factor } \beta \text { I (TGF- } \beta \text { I), } \\
\text { soluble receptor for advanced glycation } \\
\text { end products (sRAGE), plasma } \\
\text { thrombospondin (TSP)-I, circulating } \\
\text { endothelial progenitor cells (EPC) }\end{array}$ \\
\hline $\begin{array}{l}\text { Phase I (hemostasis) of } \\
\text { wound healing }\end{array}$ & $\begin{array}{l}\text { platelet derived growth factors (PDGF), } \\
\text { vascular endothelial growth factors } \\
\text { (VEGFs), fibroblast growth factors } \\
\text { (FGFs), and transforming growth } \\
\text { factors (TGFs) }\end{array}$ \\
\hline $\begin{array}{l}\text { Phase II (inflammation) of } \\
\text { wound healing }\end{array}$ & PDGF, TGF-ß, B-FGF, TNF- $\alpha$, IL-I, IL-6 \\
\hline $\begin{array}{l}\text { Phase III (proliferation) of } \\
\text { wound healing }\end{array}$ & $\begin{array}{l}\text { matrix metalloproteinases (MMPs), EGF, } \\
\text { keratinocyte growth factors (KGFs), } \\
\text { TGF- } \alpha\end{array}$ \\
\hline $\begin{array}{l}\text { Phase IV (remodeling) of } \\
\text { wound healing }\end{array}$ & Reduction in fibrinoblasts \\
\hline $\begin{array}{l}\text { Other predictors of } \\
\text { wound healing }\end{array}$ & $\begin{array}{l}\text { MMP-tissue inhibitor of metalloproteases } \\
\text { (TIMP) ratio, serpinB3 }\end{array}$ \\
\hline
\end{tabular}

\section{Declaration of Conflicting Interests}

The author(s) declared no potential conflicts of interest with respect to the research, authorship, and/or publication of this article.

\section{Funding}

The author(s) received no financial support for the research, authorship, and/or publication of this article.

\section{ORCID iD}

Constantine N. Antonopoulos (D) https://orcid.org/0000-0003-0696$695 \mathrm{X}$

\section{References}

1. Farber A. Chronic limb-threatening ischemia. $N$ Engl J Med. 2018;379(2):171-180.

2. Hoffmann U, Schulte KL, Heidrich H, Rieger H, Schellong S. Complete ulcer healing as primary endpoint in studies on critical limb ischemia? A critical reappraisal. Eur J Vasc Endovasc Surg. 2007;33(3):311-316; discussion 7-8.

3. Halliday A, Bax JJ. The 2017 ESC guidelines on the diagnosis and treatment of peripheral arterial diseases, in collaboration with the European Society for Vascular Surgery (ESVS). Eur J Vasc Endovasc Surg. 2018;55(3):301-302.

4. Soderstrom M, Arvela E, Alback A, Aho PS, Lepantalo M. Healing of ischaemic tissue lesions after infrainguinal bypass surgery for critical leg ischaemia. Eur J Vasc Endovasc Surg. 2008;36(1): 90-95.

5. Greaves NS, Ashcroft KJ, Baguneid M, Bayat A. Current understanding of molecular and cellular mechanisms in fibroplasia and angiogenesis during acute wound healing. J Dermatol Sci. 2013; 72(3):206-217.
6. Thomas Hess C. Checklist for factors affecting wound healing. Adv Skin Wound Care. 2011;24(4):192.

7. Liu S, He CZ, Cai YT, et al. Evaluation of negative-pressure wound therapy for patients with diabetic foot ulcers: systematic review and meta-analysis. Ther Clin Risk Manag. 2017;13:533-544.

8. Liu Z, Dumville JC, Hinchliffe RJ, et al. Negative pressure wound therapy for treating foot wounds in people with diabetes mellitus. Cochrane Database Syst Rev. 2018;10:CD010318.

9. Abbas M, Uckay I, Lipsky BA. In diabetic foot infections antibiotics are to treat infection, not to heal wounds. Expert Opin Pharmacother. 2015;16(6):821-832.

10. Barwell ND, Devers MC, Kennon B, et al. Diabetic foot infection: antibiotic therapy and good practice recommendations. Int J Clin Pract. 2017;71(10):1-10.

11. Zhao D, Luo S, Xu W, Hu J, Lin S, Wang N. Efficacy and safety of hyperbaric oxygen therapy used in patients with diabetic foot: a meta-analysis of randomized clinical trials. Clin Ther. 2017; 39(10):2088-2094.e2.

12. Huang ET, Mansouri J, Murad MH, et al. A clinical practice guideline for the use of hyperbaric oxygen therapy in the treatment of diabetic foot ulcers. Undersea Hyperb Med. 2015;42(3): 205-247.

13. de Oliveira AL, Moore Z. Treatment of the diabetic foot by offloading: a systematic review. J Wound Care. 2015;24(12):560, 562-570.

14. Kobayashi N, Hirano K, Nakano M, et al. Clinical effect of wound depth in critical limb ischemia with tissue loss after endovascular treatment. J Vasc Surg. 2015;62(6):1564-1574.

15. Mills JL Sr, Conte MS, Armstrong DG, et al. The society for vascular surgery lower extremity threatened limb classification system: risk stratification based on Wound, Ischemia, and foot Infection (WIfI). J Vasc Surg. 2014;59(1):220-234.e1-2.

16. Spillerova K, Biancari F, Leppaniemi A, Alback A, Soderstrom M, Venermo M. Differential impact of bypass surgery and angioplasty on angiosome-targeted infrapopliteal revascularization. Eur J Vasc Endovasc Surg. 2015;49(4):412-419.

17. Vairamon SJ, Babu M, Viswanathan V. Oxidative stress markers regulating the healing of foot ulcers in patients with type 2 diabetes. Wounds. 2009;21(10):273-279.

18. Anderson K, Hamm RL. Factors that impair wound healing. $J \mathrm{Am}$ Coll Clin Wound Spec. 2012;4(4):84-91.

19. Hangaard S, Rasmussen A, Almdal T, et al. Standard complication screening information can be used for risk assessment for first time foot ulcer among patients with type 1 and type 2 diabetes. Diabetes Res Clin Pract. 2019;151:177-186.

20. Dhatariya KK, Li Ping Wah-Pun Sin E, Cheng JOS, et al. The impact of glycaemic variability on wound healing in the diabetic foot - a retrospective study of new ulcers presenting to a specialist multidisciplinary foot clinic. Diabetes Res Clin Pract. 2018;135: 23-29.

21. Mohapatra A, Boitet A, Malak O, et al. Peroneal bypass versus endovascular peroneal intervention for critical limb ischemia. J Vasc Surg. 2019;69(1):148-155.

22. Ahn J, Raspovic KM, Liu GT, et al. Renal function as a predictor of early transmetatarsal amputation failure [published online ahead of print December 12, 2018]. Foot Ankle Spec. 2018. 
23. Das SK, Yuan YF, Li MQ. Predictors of delayed wound healing after successful isolated below-the-knee endovascular intervention in patients with ischemic foot ulcers. J Vasc Surg. 2018; 67(4):1181-1190.

24. Wagner IJ, Szpalski C, Allen RJ Jr, et al. Obesity impairs wound closure through a vasculogenic mechanism. Wound Repair Regen. 2012;20(4):512-522.

25. Pierpont YN, Dinh TP, Salas RE, et al. Obesity and surgical wound healing: a current review. ISRN Obes. 2014;2014:638936.

26. Russell L. The importance of patients' nutritional status in wound healing. Br J Nurs. 2001;10(6 suppl): S42, S44-S49.

27. Krischak GD, Augat P, Claes L, Kinzl L, Beck A. The effects of non-steroidal anti-inflammatory drug application on incisional wound healing in rats. $J$ Wound Care. 2007;16(2):76-78.

28. Sorensen LT. Wound healing and infection in surgery: the pathophysiological impact of smoking, smoking cessation, and nicotine replacement therapy: a systematic review. Ann Surg. 2012; 255(6):1069-1079.

29. Ranzer MJ, Chen L, DiPietro LA. Fibroblast function and wound breaking strength is impaired by acute ethanol intoxication. Alcohol Clin Exp Res. 2011;35(1):83-90.

30. Reed GW, Young L, Bagh I, Maier M, Shishehbor MH. Hemodynamic assessment before and after endovascular therapy for critical limb ischemia and association with clinical outcomes. JACC Cardiovasc Interv. 2017;10(23):2451-2457.

31. Darling JD, McCallum JC, Soden PA, et al. Clinical results of single-vessel versus multiple-vessel infrapopliteal intervention. J Vasc Surg. 2016;64(6):1675-1681.

32. Weledji EP, Fokam P. Treatment of the diabetic foot - to amputate or not? BMC Surg. 2014;14:83.

33. Soderstrom M, Alback A, Biancari F, Lappalainen K, Lepantalo M, Venermo M. Angiosome-targeted infrapopliteal endovascular revascularization for treatment of diabetic foot ulcers. $J$ Vasc Surg. 2013;57(2):427-435.

34. Shiraki T, Iida O, Takahara M, et al. Predictors of delayed wound healing after endovascular therapy of isolated infrapopliteal lesions underlying critical limb ischemia in patients with high prevalence of diabetes mellitus and hemodialysis. Eur J Vasc Endovasc Surg. 2015;49(5):565-573.

35. Soderstrom M, Aho PS, Lepantalo M, Alback A. The influence of the characteristics of ischemic tissue lesions on ulcer healing time after infrainguinal bypass for critical leg ischemia. J Vasc Surg. 2009;49(4):932-937.

36. Conte MS.Discussion. Open surgical revascularization for wound healing: past performance and future directions; and critical evaluation of endovascular surgery for limb salvage. Plast Reconstr Surg. 2011;127(suppl 1):174S-176S.

37. Lejay A, Georg Y, Tartaglia E, et al. Long-term outcomes of direct and indirect below-the-knee open revascularization based on the angiosome concept in diabetic patients with critical limb ischemia. Ann Vasc Surg. 2014;28(4):983-989.

38. Elbadawy A, Ali H, Saleh M, Hasaballah A. Editor's choice - a prospective study to evaluate complete wound healing and limb salvage rates after angiosome targeted infrapopliteal balloon angioplasty in patients with critical limb ischaemia. Eur J Vasc Endovasc Surg. 2018;55(3):392-397.
39. Azuma N, Uchida H, Kokubo T, Koya A, Akasaka N, Sasajima T. Factors influencing wound healing of critical ischaemic foot after bypass surgery: is the angiosome important in selecting bypass target artery? Eur J Vasc Endovasc Surg. 2012;43(3): 322-328.

40. Spillerova K, Settembre N, Biancari F, Alback A, Venermo M. Angiosome targeted PTA is more important in endovascular revascularisation than in surgical revascularisation: analysis of 545 patients with ischaemic tissue lesions. Eur J Vasc Endovasc Surg. 2017;53(4):567-575.

41. Treiman GS, Oderich GS, Ashrafi A, Schneider PA. Management of ischemic heel ulceration and gangrene: an evaluation of factors associated with successful healing. J Vasc Surg. 2000;31(6): 1110-1118.

42. Okazaki J, Matsuda D, Tanaka K, et al. Analysis of wound healing time and wound-free period as outcomes after surgical and endovascular revascularization for critical lower limb ischemia. J Vasc Surg. 2018;67(3):817-825.

43. Kret MR, Cheng D, Azarbal AF, et al. Utility of direct angiosome revascularization and runoff scores in predicting outcomes in patients undergoing revascularization for critical limb ischemia. J Vasc Surg. 2014;59(1):121-128.

44. Neville RF, Attinger CE, Bulan EJ, Ducic I, Thomassen M, Sidawy AN. Revascularization of a specific angiosome for limb salvage: does the target artery matter? Ann Vasc Surg. 2009; 23(3):367-373.

45. Atar E, Siegel Y, Avrahami R, Bartal G, Bachar GN, Belenky A. Balloon angioplasty of popliteal and crural arteries in elderly with critical chronic limb ischemia. Eur J Radiol. 2005;53(2): 287-292.

46. Mlekusch W, Schillinger M, Sabeti S, Maca T, Ahmadi R, Minar E. Clinical outcome and prognostic factors for ischaemic ulcers treated with PTA in lower limbs. Eur J Vasc Endovasc Surg. 2002;24(2):176-181.

47. Brochado Neto FC, Gonzalez J, Cinelli M Jr., Albers M. Bypass to the genicular arteries for revascularisation of the lower limb. Eur J Vasc Endovasc Surg. 2000;20(6):545-549.

48. Nicoloff AD, Taylor LM Jr., McLafferty RB, Moneta GL, Porter JM. Patient recovery after infrainguinal bypass grafting for limb salvage. J Vasc Surg. 1998;27(2):256-263; discussion 64-6.

49. Hanna GP, Fujise K, Kjellgren O, et al. Infrapopliteal transcatheter interventions for limb salvage in diabetic patients: importance of aggressive interventional approach and role of transcutaneous oximetry. J Am Coll Cardiol. 1997;30(3):664-669.

50. London NJ, Varty K, Sayers RD, Thompson MM, Bell PR, Bolia A. Percutaneous transluminal angioplasty for lower-limb critical ischaemia. Br J Surg. 1995;82(9):1232-1235.

51. Krishna SM, Moxon JV, Golledge J. A review of the pathophysiology and potential biomarkers for peripheral artery disease. Int J Mol Sci. 2015;16(5):11294-11322.

52. Patel S, Maheshwari A, Chandra A. Biomarkers for wound healing and their evaluation. $J$ Wound Care. 2016;25(1):46-55.

53. Fadini GP, Albiero M, Millioni R, et al. The molecular signature of impaired diabetic wound healing identifies serpinB3 as a healing biomarker. Diabetologia. 2014;57(9):1947-1956. 
54. Pan X, Chen G, Wu P, Han C, Ho JK. Skin perfusion pressure as a predictor of ischemic wound healing potential. Biomed Rep. 2018; 8(4):330-334.

55. Yamamoto K, Kawahara T, Akai A, et al. Increase in skin perfusion pressure predicts amputation-free survival after lower extremity bypass surgery for critical limb ischemia. Vasc Med. 2018; 23(3):243-249.

56. Terasaki H, Inoue $\mathrm{Y}$, Sugano $\mathrm{N}$, et al. A quantitative method for evaluating local perfusion using indocyanine green fluorescence imaging. Ann Vasc Surg. 2013;27(8):1154-1161.
57. Venermo M, Settembre N, Alback A, et al. Pilot assessment of the repeatability of indocyanine green fluorescence imaging and correlation with traditional foot perfusion assessments. Eur $J$ Vasc Endovasc Surg. 2016;52(4):527-533.

58. Settembre N, Kauhanen P, Alback A, Spillerova K, Venermo M. Quality control of the foot revascularization using indocyanine green fluorescence imaging. World J Surg. 2017;41(7): 1919-1926.

59. Rother U, Lang W. Noninvasive measurements of tissue perfusion in critical limb ischemia. Gefasschirurgie. 2018;23(Suppl 1):8-12. 